\title{
Association between ESR1 and ESR2 gene polymorphisms and hyperlipidemia in Chinese Han postmenopausal women
}

\author{
Teng Zhao ${ }^{1}$, Di Zhang ${ }^{1}$, Yun Liu ${ }^{1}$, Daizhan Zhou ${ }^{1}$, Zhuo Chen ${ }^{1}$, Yifeng Yang ${ }^{1}$, Sheng $\mathrm{Li}^{1}$, Lan $\mathrm{Yu}^{1}$, \\ Zuofeng Zhang ${ }^{2}$, Guoyin Feng ${ }^{3}$, Lin $\mathrm{He}^{1,3,4}$ and $\mathrm{He} \mathrm{Xu}^{1,3}$
}

Estrogen was considered to be an important protective factor for cardiovascular diseases in women. Genetic association studies suggested that variations of ESR1 and ESR2 genes might have a potential role in lipid profile. Our study aimed to investigate the association of single-nucleotide polymorphisms (SNPs) of ESR1 and ESR2 with hyperlipidemia in Chinese Han postmenopausal women. A total of 443 postmenopausal women aged between 55 and 71 years were recruited from Shanghai, China for a casecontrol study (154 women with hyperlipidemia and 289 controls). We measured plasma estradiol concentration, glucose and lipid profile levels, evaluated their lifestyle and sequenced four SNPs, namely Pvull (rs2234693) and Xbal (rs9340799) of ESR1 and $1082 A>G$ (rs 1256049) and 1730A $>$ G (rs4986938) of ESR2. Pvull (rs2234693) and Xbal (rs9340799) showed significantly different distributions between cases and controls $(P=0.002$ and $P=0.023$, respectively). In addition, haplotypes constructed from Pvull-Xbal were also associated with hyperlipidemia (global $P=0.012$ ). Haplotypes T-A $(P=0.005$, odds ratio (OR) 1.52, $95 \%$ confidence interval $(95 \% \mathrm{Cl}): 1.13-2.05)$ and $\mathrm{C}-\mathrm{G}(P=0.010,0 \mathrm{R} 0.62,95 \% \mathrm{Cl}: 0.43-0.89)$ had susceptible and protective effects, respectively. 1082A $>G($ rs 1256049) and 1730A $>G$ (rs4986938) showed no statistical association with hyperlipidemia. In conclusion, our results suggested that ESR1 might have a potential role in hyperlipidemia risk, independent of age, estradiol level, body mass index and lifestyle in Chinese Han postmenopausal women.

Journal of Human Genetics (2010) 55, 50-54; doi:10.1038/jhg.2009.122; published online 20 November 2009

Keywords: Chinese; estrogen receptor; hyperlipidemia; single-nucleotide polymorphism

\section{INTRODUCTION}

Incidence and mortality due to cardiovascular diseases (CVDs) are much higher in men than in women before menopausal age. However, the gender difference diminishes when women go into postmenopause. ${ }^{1,2}$ This phenomenon is widely believed to result from the protective effects of estrogen. There are many possible mechanisms for the protective effects of estradiol on vasculature, including increased vasodilatation by its positive influence on endothelial nitric oxide (NO) synthase and subsequent production of NO. ${ }^{3}$ Moreover, estradiol reduces the development of early lesions of atherosclerosis, through an improvement in the blood lipid profile, which reduces lipid deposits in the endothelium, with a decrease in total cholesterol and low-density lipoprotein cholesterol (LDL-C) and an increase in high-density lipoprotein cholesterol (HDL-C) in the plasma. ${ }^{4}$ The physiological process of estrogen works by binding to estrogen receptors. ${ }^{5}$ There are two known estrogen receptors, namely estrogen receptor- $\alpha$ (ESR1) and estrogen receptor- $\beta$ (ESR2), which are transcription factors and are expressed in a wide range of tissues, including macrophages, adipose cells, vascular smooth muscle and vascular endothelial cells. ${ }^{6}$ It was reported that fewer estrogen receptors were found in premenopausal women with atherosclerotic coronary arteries than in those with normal coronary arteries. ${ }^{7}$ Recently, a genome-wide association study of plasma lipoprotein(a) suggested a complex genetic architecture of plasma lipoprotein(a) levels that might involve multiple loci on chromosome 6q26-q27 in which the ESR1 gene is located. ${ }^{8}$ A number of independent studies that investigated the effects of single-nucleotide polymorphisms (SNPs) of ESR1 and ESR2 genes on estrogen-related characteristics had shown some interesting SNPs, such as PvuII (rs2234693) and XbaI (rs9340799) of ESR1 and 1082A > G (rs1256049) and 1730A > G (rs4986938) of ESR2 and so on. The PvuII (rs2234693) polymorphism may affect the binding of the transcription factor, resulting in the alteration of protein expression. ${ }^{9}$ PvuII (rs2234693) and XbaI (rs9340799) of ESR1 were reported to be associated with lipid

${ }^{1}$ Institute for Nutritional Sciences, Shanghai Institutes for Biological Sciences, Chinese Academy of Sciences, Shanghai, PR China; ${ }^{2}$ Department of Epidemiology, UCLA School of Public Health, Los Angeles, CA, USA; ${ }^{3}$ Bio-X Center, Key Laboratory for the Genetics of Developmental and Neuropsychiatric Disorders (Ministry of Education), Shanghai Jiao Tong University, Shanghai, PR China and ${ }^{4}$ Institutes of Biomedical Sciences, Fudan University, Shanghai, PR China

Correspondence: Dr H Xu or Dr L He, Institute for Nutritional Sciences, Shanghai Institutes for Biological Sciences, Chinese Academy of Sciences, 294 Taiyuan Road, Shanghai 200031, PR China or Bio-X Center, Shanghai Jiao Tong University, Hao Ran Building, 1954 Hua Shan Road, Shanghai 200030, PR China or Institutes of Biomedical Sciences Fudan University, 138 Yixueyuan Road, Shanghai 200032, PR China.

E-mail: xuhe@sibs.ac.cn or helin@bio-x.cn

Received 30 August 2009; revised 29 September 2009; accepted 21 October 2009; published online 20 November 2009 
profile, ${ }^{10-13}$ Alzheimer's disease, ${ }^{14}$ artery wall atherosclerosis, ${ }^{15}$ atherosclerotic severity to hormone replacement therapy (HRT) ${ }^{16}$ and pathogenesis of hypertension, ${ }^{17,18}$ stroke, ${ }^{19} \mathrm{CVDs}^{20-23}$ and type II diabetes. $^{24,25}$ 1082A $>\mathrm{G}(\mathrm{rs} 1256049)$ and $1730 \mathrm{~A}>\mathrm{G}(\mathrm{rs} 4986938)$ of ESR2 might have a role in CVDs ${ }^{26,27}$ and lipid profile. ${ }^{28,29}$

Most of the evidence was reported from the Western population; however, little was known about the SNP distributions of ESRs and their relationships with hyperlipidemia in Chinese women. In our study, we measured serum estrogen concentration and sequenced four representative SNPs, namely PvuII (rs2234693) and XbaI (rs9340799) of ESR1 and 1082A > G (rs1256049) and 1730A > G (rs4986938) of ESR2. We aimed to investigate the association of SNPs of ESR1 and ESR2 genes with hyperlipidemia in a Chinese Han postmenopausal women population.

\section{MATERIALS AND METHODS}

\section{Population and DNA preparation}

A total of 443 Chinese Han postmenopausal women aged between 55 and 71 years were recruited from Shanghai, China, including 154 hyperlipidemia cases and 289 controls. Eligible candidates were defined as those who were stable residents in the area and without the following conditions: severe psychological disorders, physical disabilities, cancer, diabetes mellitus, CVDs, Alzheimer's disease or dementia, within 6 months; or currently diagnosed with tuberculosis, AIDs (acquired immune deficiency syndrome) or other communicable diseases. They did not take lipid-lowering medicines; neither did they undergo HRT. All cases were diagnosed according to the National Cholesterol Education Program Adult Treatment Panel III (NCEP ATP III) criteria. ${ }^{30}$ Controls were nonhyperlipidemic and were recruited from the same districts of Shanghai as were the cases. Main clinical data including age, sex, body mass index (BMI), waist circumference, systolic and diastolic blood pressures, smoking history, alcohol drinking and physical activity were recorded. Total cholesterol, HDL-C, LDL-C, triglyceride, glucose levels, C-reactive protein (CRP) and estradiol concentrations were determined from fasting blood samples of all participants.

We certified that all applicable institutional and governmental regulations with regard to the ethical use of human volunteers were followed during this research. A standard written informed consent, reviewed and approved by the ethics committee of the Shanghai Institute for Biological Sciences, Chinese Academy of Sciences, was obtained from all participating subjects who were given a full explanation of the study.

High-molecular-weight genomic DNA was prepared from venous blood using the QuickGene 610L Automatic DNA/RNA Extraction System (Fijifilm, Tokyo, Japan).

\section{Genotyping}

The minor allele frequencies of rs2234693, rs9340799, rs1256049 and rs4986938 were $0.402,0.225,0.299$ and 0.128 , respectively, in the Chinese Han population according to the dbSNP database (http://www.ncbi.nlm.nih.gov/SNP/) and the hapmap human SNP database (http://www.hapmap.org/). We amplified a 470-bp genomic segment for the rs2234693 (T/C) and rs9340799 (A/G) polymorphisms (upstream primer 5'-CATGAACCACCATGCTCAGT-3', downstream primer 5'-TTACCTCTTGCCGTCTGTTG-3'), a 475-bp genomic segment for the rs $1256049(\mathrm{~A} / \mathrm{G})$ polymorphism (upstream primer $5^{\prime}$-TTCTG AGCCGAGGTCGTAGT-3', downstream primer 5'-CCAGGACTTTGTTCCCA CTC-3') and a 293-bp genomic segment for the rs4986938 (A/G) polymorphism (upstream primer 5'-CCGGCAGAGGACAGTAAAAG-3', downstream primer $5^{\prime}$-AGGCCATTGAGTGTGGAAAC-3'). PCR was performed using the GeneAmp 9700 System (Applied Biosystems, Foster City, CA, USA) in a $15 \mu 1$ reaction, containing $10 \mathrm{ng}$ genomic DNA, $1.2 \mathrm{U}$ Taq polymerase, $0.25 \mu \mathrm{l}$ of each primer (10 pM), $2.5 \mu$ PCR buffer (10×, Qiagen, Valencia, CA, USA) and $1.5 \mu \mathrm{l}$ dNTPs (each $2 \mathrm{~mm}$ ). The amplification process began with an initial 10-min denaturation at $94^{\circ} \mathrm{C}$, followed by replication of 35 cycles of $30 \mathrm{~s}$ at $94^{\circ} \mathrm{C}, 40 \mathrm{~s}$ at $60^{\circ} \mathrm{C}$ and $40 \mathrm{~s}$ at $72{ }^{\circ} \mathrm{C}$, and ended with an extension period at $72{ }^{\circ} \mathrm{C}$ for $7 \mathrm{~min}$ for both SNPs. The PCR products for sequencing were incubated with 0.1-U shrimp alkaline phosphatase at $37^{\circ} \mathrm{C}$ for $60 \mathrm{~min}$, followed by heat inactivation at $85^{\circ} \mathrm{C}$ for $20 \mathrm{~min}$. The treated PCR products were sequenced using an ABI Prism BigDye Terminator Cycle Sequencing Kit, version 3.1 (Applied Biosystems) on an ABI Prism 3100 sequencer (Applied Biosystems).

We conducted a duplicate quality control test (48 samples for each SNP), which reported $100 \%$ concordance.

\section{Statistical analysis}

Hardy-Weinberg equilibrium testing and allele and genotype frequency analysis were carried out online on a robust and user-friendly software platform (http:// analysis.bio-x.cn/) developed by our laboratory. ${ }^{31}$ It was used to estimate linkage disequilibrium (LD) measured with standardized $D^{\prime}$ and to compare the discrepancies of allele, genotype and haplotype frequencies on SNPs between cases and controls using the $\chi^{2}$-test and the odds ratio (OR) test. Further genetic analysis procedures adjusted for age, estradiol level, BMI, smoking, alcohol consumption and exercise were assessed with a multivariate logistic regression model. For the additive model, homozygotes (1/1), heterozygotes $(1 / 0)$ for the risk allele and homozygotes for the non-risk allele $(0 / 0)$ were encoded to an ordered categorical variable for genotypes $(2,1$ and 0$)$. For rs2234693, $\mathrm{TT}=2, \mathrm{CT}=1, \mathrm{CC}=0$; for $\mathrm{rs} 9340799, \mathrm{AA}=2, \mathrm{AG}=1, \mathrm{GG}=0$; for rs 1256049, $A A=2, A G=1, G G=0$; for $r$ s $4986938, A A=2, A G=1, G G=0$. The dominant model was defined as $1 / 1+1 / 0$ versus $0 / 0$ and the recessive model as $1 / 1$ versus $1 / 0+0 / 0$. For rs $2234693, \mathrm{TT}+\mathrm{CT}=2, \mathrm{CC}=1$ in the dominant model and $\mathrm{TT}=2, \mathrm{CT}+\mathrm{CC}=1$ in the recessive model. Other SNPs were of similar analogy. The difference in quantitative traits, including BMI, triglycerides (Trig), cholesterol (Cho), HDL-C, LDL-C, CRP and estradiol concentration as the dependent variable, was analyzed by the Wilcoxon rank-sum test and the Kruskal-Wallis test, with genotype as the independent variable. Statistical analyses were carried out using the SPSS (SPSS, Chicago, IL, USA) program.

Power calculations were post hoc calculations performed on the $\mathrm{G}^{*}$ Power program. ${ }^{32}$ All $P$-values reported were two-tailed. Statistical significance was defined as $P<0.05$.

\section{RESULTS}

A total of 443 Chinese Han postmenopausal women aged between 55 and 71 years were recruited from Shanghai, China, including 154 cases (mean age 60.1 years, s.d. $=2.9$ ) and 289 controls (mean age 59.3 years, s.d.=2.6). The clinical characteristics of participants are summarized in Table 1.

Genotype distributions of the four SNPs in cases and controls were in Hardy-Weinberg equilibrium $(P>0.05)$. In power calculations using the $G^{\star}$ Power 3 program, we found that the sample size had $>76 \%$ power for $\mathrm{rs} 2234693,>60 \%$ for $\mathrm{rs} 9340799,>68 \%$ for rs 1256049 and $>54 \%$ for rs4986938 to detect a weak gene effect $(\mathrm{OR}=1.3)$ with $\alpha \leqslant 0.05$.

We found significant differences in allele frequencies of PvuII (rs2234693) and XbaI (rs9340799) between cases and controls in Chinese Han postmenopausal women. The frequency of the T allele of PvuII (rs2234693) was significantly higher in patients $(67.0 \%)$ than in controls $(56.9 \%)(P=0.004$, OR $1.54,95 \%$ confidence interval $(95 \%$ $\mathrm{CI}): 1.15-2.07)$, as was the A allele of XbaI (rs9340799) $(P=0.023$, OR 1.50, 95\% CI: 1.06-2.14). These discrepancies remained in genotype distribution in additive, dominant and recessive models before or after adjusting for age, estradiol level, BMI, smoking, alcohol consumption and exercise (Table 2). Furthermore, model selection examination was performed by Akaike's information criterion, suggesting the propriety of the additive model for the two SNPs. We did not find any significant differences in either allele or genotype frequencies of $1082 \mathrm{~A}>\mathrm{G}$ ( $\mathrm{rs} 1256049)$ and $1730 \mathrm{~A}>\mathrm{G}$ (rs4986938) between cases and controls in additive, dominant and recessive models either before or after adjusting for age, estradiol level, BMI, smoking, alcohol consumption and exercise.

In addition, the estimation of LD for all pairs of SNP markers showed that PvuII (rs2234693) and XbaI (rs9340799) of ESR1 were in a relatively strong $\mathrm{LD}$ relationship with the standardized $D^{\prime}=0.94$, as 
well as 1082A $>\mathrm{G}(\mathrm{rs} 1256049)$ and $1730 \mathrm{~A}>\mathrm{G}$ (rs4986938) of ESR2 with the standardized $D^{\prime}=0.99$. We further analyzed the frequency distributions of haplotypes of the four SNPs above the common lowest frequency threshold (those with a frequency $<0.03$ will not be included in the analysis). Haplotypes constructed from PvuII-XbaI were associated with hyperlipidemia (global $P=0.012$ ), and two of them, haplotype T-A $(P=0.005$, OR $1.52,95 \%$ CI: $1.13-2.05)$ and $\mathrm{C}-\mathrm{G}(P=0.010$, OR $0.62,95 \% \mathrm{CI}$ : $0.43-0.89)$ with reference to all other haplotypes, were very significant. 1082A $>\mathrm{G}$ (rs1256049), $1730 \mathrm{~A}>\mathrm{G}$ (rs4986938) and haplotypes of $1082 \mathrm{~A}>\mathrm{G}-1730 \mathrm{~A}>\mathrm{G}$ showed no statistical association with hyperlipidemia (Table 3 ).

According to the NCEP ATP III criteria, hyperlipidemia is defined by four components that we were also concerned about. We specifically examined the relationship between the four SNPs and BMI, triglyceride (Trig), cholesterol (Cho), HDL-C (HDL), LDL-C (LDL), CRP and estradiol concentration in all postmenopausal women using the Wilcoxon rank-sum test and the Kruskal-Wallis test. No significant associations of the polymorphisms of ESR1 or ESR2 with metabolic quantitative traits were observed (Supplement 1).

Table 1 Clinical characteristics of the participants

\begin{tabular}{lcrr}
\hline & Hyperlipidemia & Control & P-value \\
\hline Age (years) & $60.1 \pm 2.9$ & $59.3 \pm 2.6$ & 0.003 \\
Estradiol (pmol I-1) & $15.7 \pm 7.6$ & $15.4 \pm 7.0$ & 0.706 \\
Fasting blood glucose (mmol I-1) & $4.9 \pm 0.6$ & $4.9 \pm 0.6$ & 0.966 \\
HbA1C (\%) & $5.9 \pm 0.5$ & $5.8 \pm 0.5$ & 0.396 \\
Systolic BP (mm Hg) & $133 \pm 18$ & $129 \pm 18$ & 0.059 \\
Diastolic BP (mm Hg) & $82 \pm 9$ & $80 \pm 10$ & 0.065 \\
BMI (kg m-2) & $25.6 \pm 2.9$ & $24.4 \pm 3.5$ & $<0.001$ \\
Waist (cm) & $85.9 \pm 7.5$ & $81.6 \pm 9.2$ & $<0.001$ \\
Cholesterol (mmol I-1) & $5.0 \pm 1.2$ & $4.6 \pm 0.6$ & $<0.001$ \\
Triglycerides (mmol I-1) & $2.6 \pm 1.3$ & $1.3 \pm 0.4$ & $<0.001$ \\
LDL (mmol I-1) & $3.2 \pm 1.1$ & $3.0 \pm 0.6$ & 0.080 \\
HDL (mmol I-1) & $1.1 \pm 0.3$ & $1.4 \pm 0.3$ & $<0.001$
\end{tabular}

Abbreviations: BMI, body mass index; BP, blood pressure; HbA1C, hemoglobin A1C, HDL, highdensity lipoprotein; LDL, low-density lipoprotein.

Data are means \pm s.d.

\section{DISCUSSION}

Hyperlipidemia is the presence of increased or abnormal levels of lipids and/or lipoproteins in the blood and a strong risk factor for atherosclerosis, stroke, CAD and myocardial infarction (MI), as reported by epidemiological studies. ${ }^{30}$ However, the risk has gender differences. Are women superior to men with regard to the risk of CVD? Research evidence suggests so. The incidence of CVD among women is low before menopause but steadily increases after the onset of menopause. This increase is believed to result partly from the loss of endogenous estrogen, which is involved in cardio-protective effects. Endogenous and exogenous estrogens decrease LDL-C, increase HDL$\mathrm{C}$ levels and lead to an increment in mRNA for the LDL receptor. ${ }^{33}$ Estrogen works by binding to estrogen receptors and carries out direct and indirect effects on cardiovascular tissues through mechanisms involving genomic and nongenomic pathways. ${ }^{34}$ It was reported that fewer estrogen receptors were found in premenopausal women with atherosclerotic coronary arteries than in those with normal coronary arteries. ${ }^{7}$ Recently, a genome-wide association study of plasma lipoprotein(a) suggested a complex genetic architecture of plasma lipoprotein(a) levels that might involve multiple loci on chromosome 6q26-q27, in which the ESR1 gene is located. ${ }^{8}$

In our study, we found a positive association between polymorphisms of ESR1 and hyperlipidemia in Chinese Han postmenopausal

Table 3 The estimated haplotype distributions in cases and controls

\begin{tabular}{lccccc}
\hline SNPs & Haplotype & Case (freq) & Control (freq) & $\begin{array}{c}\text { Global } \\
\text { P-value }\end{array}$ & P-value \\
\hline ESR1 & C-A & $49.69(0.169)$ & $106.49(0.193)$ & 0.012 & 0.423 \\
Pvull-Xbal & C-G & $47.31(0.161)$ & $131.51(0.238)$ & & 0.010 \\
& T-A & $193.31(0.658)$ & $311.51(0.564)$ & & 0.005 \\
ESR2 & A-G & $93.98(0.313)$ & $173.98(0.314)$ & 0.460 & 0.982 \\
$1082 A>$ G & G-A & $47.98(0.160)$ & $71.98(0.130)$ & & 0.228 \\
$-1730 A>$ G & & & & & \\
& G-G & $158.02(0.527)$ & $308.02(0.556)$ & & 0.413
\end{tabular}

Abbreviation: SNP, single-nucleotide polymorphism.

Haplotypes are of at least $3 \%$ frequency in both case and control groups. $P$-values $(<0.05)$ are in bold.

Table 2 Allele and genotype distributions of the SNPs in hyperlipidemia and controls

\begin{tabular}{|c|c|c|c|c|c|c|c|c|c|c|}
\hline \multirow[b]{2}{*}{ SNPS } & \multirow[b]{2}{*}{$\begin{array}{l}\text { Risk } \\
\text { allele }\end{array}$} & \multicolumn{2}{|c|}{ Risk allele frequencies } & \multirow[b]{2}{*}{$\begin{array}{l}\text { Unadjusted } \\
\text { OR }(95 \% \text { Cl) }\end{array}$} & \multirow[b]{2}{*}{ Genotype } & \multicolumn{2}{|c|}{ Genotype distribution } & \multicolumn{3}{|c|}{ Adjusted $O R^{\mathrm{a}}$} \\
\hline & & $\begin{array}{l}\text { Control } \\
\mathrm{n} \text { (freq) }\end{array}$ & $\begin{array}{c}\text { Hyperlipidemia } \\
\text { n (freq) }\end{array}$ & & & $\begin{array}{l}\text { Control } \\
\text { n (freq) }\end{array}$ & $\begin{array}{c}\text { Hyperlipidemia } \\
\text { n freq) }\end{array}$ & $\begin{array}{c}\text { Additive model } \\
\text { OR }(95 \% \mathrm{Cl})\end{array}$ & $\begin{array}{l}\text { Dominant model } \\
\text { OR }(95 \% \mathrm{Cl})\end{array}$ & $\begin{array}{c}\text { Recessive model } \\
\text { OR }(95 \% \mathrm{Cl})\end{array}$ \\
\hline \multirow[t]{3}{*}{ ESR1 Pvull } & $\mathrm{T}$ & $315(0.569)$ & $197(0.670)$ & $1.54(1.15-2.07)$ & $\mathrm{TT}$ & $94(0.339)$ & $67(0.456)$ & $1.61(1.19-2.18)$ & $2.28(1.24-4.21)$ & $1.73(1.13-2.66)$ \\
\hline & & & & $P_{\text {freq }}=0.004$ & $\mathrm{CT}$ & $127(0.458)$ & $63(0.429)$ & $P_{\text {add }}=0.002$ & $P_{\text {dom }}=0.008$ & $P_{\text {rec }=} 0.012$ \\
\hline & & & & & $\mathrm{CC}$ & $56(0.202)$ & $17(0.116)$ & & & \\
\hline \multirow[t]{3}{*}{ ESR1 Xbal } & A & $438(0.760)$ & $253(0.827)$ & $1.50(1.06-2.14)$ & $\mathrm{AA}$ & $164(0.569)$ & $102(0.667)$ & $1.70(1.16-2.49)$ & $4.94(1.03-23.7)$ & $1.65(1.08-2.53)$ \\
\hline & & & & $P_{\text {freq }}=0.023$ & $\mathrm{GA}$ & $110(0.382)$ & $49(0.320)$ & $P_{\mathrm{add}}=0.007$ & $P_{\mathrm{dom}}=0.046$ & $P_{\text {rec }=0.022}$ \\
\hline & & & & & GG & $14(0.049)$ & $2(0.013)$ & & & \\
\hline ESR2 & A & $182(0.316)$ & $94(0.307)$ & $1.04(0.77-1.41)$ & $\mathrm{AA}$ & $30(0.104)$ & $11(0.072)$ & $0.94(0.68-1.29)$ & $1.06(0.70-1.59)$ & $0.60(0.28-1.29)$ \\
\hline \multirow[t]{2}{*}{$1082 A>G$} & & & & $P_{\text {freq }}=0.789$ & $A G$ & $122(0.424)$ & $72(0.471)$ & $P_{\text {add }}=0.692$ & $P_{\text {dom }}=0.796$ & $P_{\text {rec }}=0.191$ \\
\hline & & & & & GG & $136(0.472)$ & $70(0.458)$ & & & \\
\hline ESR2 & A & $72(0.130)$ & $48(0.159)$ & $1.27(0.85-1.88)$ & $\mathrm{AA}$ & $5(0.018)$ & $6(0.040)$ & $1.24(0.83-1.85)$ & $1.18(0.74-1.88)$ & $2.47(0.70-8.75)$ \\
\hline \multirow[t]{2}{*}{$1730 A>G$} & & & & $P_{\text {freq }}=0.243$ & $A G$ & $62(0.224)$ & $36(0.238)$ & $P_{\text {add }}=0.291$ & $P_{\text {dom }}=0.483$ & $P_{\text {rec }}=0.162$ \\
\hline & & & & & GG & $210(0.758)$ & $109(0.722)$ & & & \\
\hline
\end{tabular}

Abbreviations: BMI, body mass index; $\mathrm{Cl}$, confidence interval; OR, odds ratio; SNP, single-nucleotide polymorphism.

$P<0.05$ are in bold.

aAjusted with age, estradiol level, BMI, smoking, alcohol consumption and exercise. 
women. Women who carried the PvuII $\mathrm{T}$ allele of ESR1 had an increased risk of hyperlipidemia. After adjusting for age, estradiol level, BMI, smoking, alcohol consumption and exercise, genotype distribution was still significantly different between cases and controls in additive, dominant and recessive models. Positive associations were also found at XbaI of ESR1, which was close to and at LD with PvuII. Recently, Demissie et al. ${ }^{35}$ reported that women with the PvuII T allele had a higher small LDL particle concentration. Our results were consistent with those of previous studies and suggested that ESR1 had an important role in lipid profile. In addition, further analysis on haplotypes in our study validated the positive association of PvuII-XbaI with hyperlipidemia. Although the above associations could be eliminated after strict Bonferroni's correction $(\times 22)$, the results still had marginal significance. A larger sample with enhanced detecting power and comprehensive meta-analysis should be helpful in understanding the association between polymorphisms of ESR1 and hyperlipidemia.

A possible mechanism to influence ESR1 expression is the altered binding of transcription or splicing of mRNA. The PvuII SNP of ESR1, along with XbaI, is located upstream of exon2 of the ESR1 gene. Herrington et al. ${ }^{9}$ reported that the PvuII T allele eliminated a functional binding site for the transcription factor B-myb, which suggested that the presence of this allele was likely to result in a lower ESR1 transcription. In the absence of estrogen receptors, estrogen signaling is likely to undertake negative feedback and, therefore, estrogen actions are decreased. This finding was supported by investigations on myocardial infarction, ${ }^{22}$ osteoporosis, ${ }^{36}$ shorter stature ${ }^{37}$ and later age at menopause. ${ }^{38}$ In addition, it was reported that estrogen repressed the transcription of the hepatic lipase gene. ${ }^{39}$ Therefore, decreased estrogen activity involved with the $\mathrm{T}$ allele probably results in elevated hepatic lipase activity and consequently increases the mass and percentage of LDL as reported. ${ }^{35}$

In previous studies, Shearman et al. ${ }^{21}$ reported that the PvuII C allele was predisposed to MI and stroke ${ }^{40}$ in men, which was seemingly contradictory to our finding that the $\mathrm{T}$ allele increased the risk of hyperlipidemia in women. However, the results were not as completely conflicting as they seemed. Schuit et al. reported that T-allele women carriers had substantial increased risk of MI, and they explained the discrepancy between men and women with a reasonable hypothesis. In men, compared with postmenopausal women of the same age, estradiol levels were approximately three times higher. In the presence of steady and sufficient estradiol levels, men might not be influenced by an altered ESR1 expression. However, a sharp estrogen deficiency after menopause, accompanied by a lower ESR1 expression caused by the PvuII T allele, might lead to a higher susceptibility to CVDs. ${ }^{22}$ Recently, a study further showed the possible mechanism involved with adiponectin. The T allele of PvuII was associated with low serum levels of adiponectin, which might lead to a high risk of CVD in postmenopausal women. ${ }^{41}$ Moreover, Hayashi et al. ${ }^{42}$ reported that only women with a TT genotype had increased arterial stiffness, whereas men did not. Ferrero et al. ${ }^{43}$ reported that women homozygous for the $\mathrm{T}$ allele treated with coronary stent implantation had a higher risk of in-stent restenosis than did men. Lamon-Fava et al. ${ }^{44}$ reported that postmenopausal women carrying the Tallele had lower HDL-C and higher plasma TG. Our results were consistent with this interesting gender-specific effect of PvuII SNP. During the postmenopausal period, when the protective effect of estrogen is lost, women with the T-allele polymorphism and a lower efficient ESR1 may be more vulnerable to lipid metabolism. On the other hand, men are not disturbed by lower ESR1, and are even more sensitive to a higher estrogen effect, namely, with the $\mathrm{C}$ allele, such as in CAD. ${ }^{20}$ Interestingly, this effect is probably driven not only endogenously but also exogenously by phytoestrogens. It was reported that soy protein intake, accompanied by soy-isoflavone, had a positive impact on hyperglycemia and metabolic syndrome in men, but had a negative impact in women. ${ }^{45}$

Little was known about the association of 1082A > G (rs1256049) and $1730 \mathrm{~A}>\mathrm{G}$ (rs4986938) of ESR2 with hyperlipidemia. Results of previous studies with regard to the association between these two SNPs and CVDs were controversial. They were reported as being associated with deep-vein thrombosis ${ }^{26}$ and $\mathrm{CVDs}^{27}$ in Caucasians. In another study, mean LDL and total cholesterol concentrations in premenopausal or postmenopausal women with higher estrogen exposure were lower in those with the GA genotype for $1082 \mathrm{~A}>\mathrm{G}$ than in those with the AA genotype in Brazilians of European descent. ${ }^{29}$ Conversely, Domingues-Montanari et al. ${ }^{46}$ reported that no association with MI was observed for $1082 \mathrm{~A}>\mathrm{G}$ or $1730 \mathrm{~A}>\mathrm{G}$ in the Spanish population. In this study, we did not find any association of $1082 \mathrm{~A}>\mathrm{G}$ (rs1256049) and 1730A $>\mathrm{G}$ (rs4986938) with hyperlipidemia. According to power calculation, false-negative results cannot be avoided adequately, unless the effect of the SNP is strong enough to detect, such as $\mathrm{OR} \geqslant 1.4$, but the real effect is probably weaker. In addition, population heterogeneity may be a factor, especially for a complicated metabolic disorder. Further studies with more tag SNPs chosen in different gene blocks of ESR2 are necessary.

According to the NCEP ATP III criteria, hyperlipidemia is defined by four components: triglyceride, total cholesterol, HDL-C and LDLC. Estrogen receptor genes and estrogen have important roles in lipid profile. ${ }^{10,13}$ We examined the relationship of four SNPs with BMI, Cho, Trig, HDL, LDL, CRP and estradiol distribution tested by the Kruskal-Wallis test. However, none showed significant association with any of the metabolic quantitative traits. We assumed that the susceptibility to hyperlipidemia, based on ESR1 gene polymorphisms, was reflected from a comprehensive lipid profile, and not separately from each component. Variations of the ESR1 gene changed not only a single character, such as triglyceride or total cholesterol, but also affected the general risk above a threshold for hyperlipidemia, and even further for other diseases. ${ }^{47}$ The main effect and discrepancy became undetectable when divided into pieces of characters. A larger sample to deliver enhanced statistical power should be helpful.

Genetic association studies are often disturbed by population stratification. In our study, all participants were of Chinese Han origin and 55-71-year-old Shanghai local residents. Therefore, our sample could be considered ethnically homogeneous.

In summary, to our knowledge, this was the first study to investigate the association of ESR1 and ESR2 gene polymorphisms with hyperlipidemia risk in the Chinese Han postmenopausal women population. Our study suggested that postmenopausal women who carried the Tallele of PvuII (rs2234693) or the A allele of XbaI (rs9340799), or the T-A haplotype of PvuII-XbaI of the ESR1 gene, had increased risk of hyperlipidemia independent of their age, estradiol level, BMI, smoking, alcohol consumption and physical activity. We hope that this study will be a reference point for further studies on hyperlipidemia and CVDs in Asian and other ethnic populations.

\section{CONFLICT OF INTEREST}

The authors declare no conflict of interest.

\section{ACKNOWLEDGEMENTS}

We appreciate the contribution of all of the members participating in this study, as well as that of the doctors who helped us in the diagnosis. This study was supported by grants from the National Natural Science Foundation of China, the national S973 and 863 Programs, Chinese Nutrition Society (05015), 
Dannon Institute, Shanghai-Unilever Research and Development Fund (06SU07007), Shanghai Municipality Science \& Technology Commission (05JC14090,07DJ14005, Shanghai Leading Academic Discipline Project (B205), the Knowledge Innovation Program of Shanghai Institutes for Biological Sciences, the Chinese Academy of Sciences (2007KIP210,2009KIP305) and the Chinese Academy of Sciences (KSCX2-YW-R-01, KSCX2-YW-N-034).

1 Maxwell, S. R. Women and heart disease. Basic Res. Cardiol. 93(Suppl 2), 79-84 (1998).

2 Kannel, W. B., Hjortland, M. C., McNamara, P. M. \& Gordon, T. Menopause and risk of cardiovascular disease: the Framingham study. Ann. Int. Med. 85, 447-452 (1976).

3 White, C. R., Shelton, J., Chen, S. J., Darley-Usmar, V., Allen, L., Nabors, C. et al. Estrogen restores endothelial cell function in an experimental model of vascular injury. Circulation 96, 1624-1630 (1997).

4 Campos, H., Walsh, B. W., Judge, H. \& Sacks, F. M. Effect of estrogen on very low density lipoprotein and low density lipoprotein subclass metabolism in postmenopausal women. J. Clin. Endocrinol. Metab. 82, 3955-3963 (1997).

5 Lahm, T., Crisostomo, P. R., Markel, T. A., Wang, M., Wang, Y., Tan, J. et al. Selective estrogen receptor-alpha and estrogen receptor-beta agonists rapidly decrease pulmonary artery vasoconstriction by a nitric oxide dependent mechanism. Am. J. Physiol. Regul. Integr. Comp. Physiol. 295, 486-493 (2008).

6 Mendelsohn, M. E. \& Karas, R. H. The protective effects of estrogen on the cardiovascular system. N. Engl. J. Med. 340, 1801-1811 (1999).

7 Losordo, D. W., Kearney, M., Kim, E. A., Jekanowski, J. \& Isner, J. M. Variable expression of the estrogen receptor in normal and atherosclerotic coronary arteries of premenopausal women. Circulation 89, 1501-1510 (1994).

8 Ober, C., Nord, A. S., Thompson, E. E., Pan, L., Tan, Z., Cusanovich, D. et al. Genomewide association study of plasma lipoprotein(a) levels identifies multiple genes on chromosome 6q. J. Lipid Res. 50, 798-806 (2009).

9 Herrington, D. M., Howard, T. D., Brosnihan, K. B., McDonnell, D. P., Li, X., Hawkins, G. A. et al. Common estrogen receptor polymorphism augments effects of hormone replacement therapy on E-selectin but not C-reactive protein. Circulation 105, 1879-1882 (2002).

10 Herrington, D. M., Howard, T. D., Hawkins, G. A., Reboussin, D. M., Xu, J., Zheng, S. L. et al. Estrogen-receptor polymorphisms and effects of estrogen replacement on highdensity lipoprotein cholesterol in women with coronary disease. N. Engl. J. Med. 346, 967-974 (2002).

11 Ntukidem, N. I., Nguyen, A. T., Stearns, V., Rehman, M., Schott, A., Skaar, T. et al. Estrogen receptor genotypes, menopausal status, and the lipid effects of tamoxifen. Clin. Pharmacol. Ther. 83, 702-710 (2008).

12 Deng, H. W., Li, J., Li, J. L., Dowd, R., Davies, K. M., Johnson, M. et al. Association of estrogen receptor-alpha genotypes with body mass index in normal healthy postmenopausal Caucasian women. J. Clin. Endocrinol. Metab. 85, 2748-2751 (2000).

13 Kikuchi, T., Hashimoto, N., Kawasaki, T. \& Uchiyama, M. Association of serum lowdensity lipoprotein metabolism with oestrogen receptor gene polymorphisms in healthy children. Acta. Paediatr. 89, 42-45 (2000).

14 Schupf, N., Lee, J. H., Wei, M., Pang, D., Chace, C., Cheng, R. et al. Estrogen receptoralpha variants increase risk of Alzheimer's disease in women with Down syndrome. Dement. Geriatr. Cogn. Disord. 25, 476-482 (2008).

15 Lehtimaki, T., Kunnas, T. A., Mattila, K. M., Perola, M., Penttila, A., Koivula, T. et al. Coronary artery wall atherosclerosis in relation to the estrogen receptor 1 gene polymorphism: an autopsy study. J. Mol. Med. 80, 176-180 (2002).

16 Koivu, T. A., Fan, Y. M., Mattila, K. M., Dastidar, P., Jokela, H., Nikkari, S. T. et al. The effect of hormone replacement therapy on atherosclerotic severity in relation to ESR1 genotype in postmenopausal women. Maturitas 44, 29-38 (2003).

17 Ogawa, S., Emi, M., Shiraki, M., Hosoi, T., Ouchi, Y. \& Inoue, S. Association of estrogen receptor beta (ESR2) gene polymorphism with blood pressure. J. Hum. Genet. 45, 327-330 (2000).

18 Tamura, M., Nakayama, T., Sato, I., Sato, N., Izawa, N., Hishiki, M. et al. Haplotypebased case-control study of estrogen receptor alpha (ESR1) gene and pregnancyinduced hypertension. Hypertens. Res. 31, 221-228 (2008).

19 Lazaros, L., Markoula, S., Xita, N., Giannopoulos, S., Gogou, P., Lagos, G. et al. Association of estrogen receptor-alpha gene polymorphisms with stroke risk in patients with metabolic syndrome. Acta. Neurologica. Scandinavica. 117, 186-190 (2008).

20 Xu, H., Hou, X., Wang, N., Hui, B., Jin, J., Yun, S. et al. Gender-specific effect of estrogen receptor-1 gene polymorphisms in coronary artery disease and its angiographic severity in Chinese population. Clinica. Chimica. Acta.; Int. J. Clin. Chem. 395, 130-133 (2008).

21 Shearman, A. M., Cupples, L. A., Demissie, S., Peter, I., Schmid, C. H., Karas, R. H. et al. Association between estrogen receptor alpha gene variation and cardiovascular disease. JAMA 290, 2263-2270 (2003).

22 Schuit, S. C., Oei, H. H., Witteman, J. C., Geurts van Kessel, C. H., van Meurs, J. B., Nijhuis, R. L. et al. Estrogen receptor alpha gene polymorphisms and risk of myocardial infarction. JAMA 291, 2969-2977 (2004).

23 Mansur, AdeP., Nogueira, C. C., Strunz, C. M., Aldrighi, J. M. \& Ramires, J. A. Genetic polymorphisms of estrogen receptors in patients with premature coronary artery disease. Arch. Med. Res. 36, 511-517 (2005).
24 Gallagher, C. J., Keene, K. L., Mychaleckyj, J. C., Langefeld, C. D., Hirschhorn, J. N., Henderson, B. E. et al. Investigation of the estrogen receptor-alpha gene with type 2 diabetes and/or nephropathy in African-American and European-American populations. Diabetes 56, 675-684 (2007).

25 Keene, K. L., Mychaleckyj, J. C., Smith, S. G., Leak, T. S., Perlegas, P. S., Langefeld, C. D. et al. Comprehensive evaluation of the estrogen receptor alpha gene reveals further evidence for association with type 2 diabetes enriched for nephropathy in an African American population. Hum. Genet. 123, 333-341 (2008).

26 Alessio, A. M., Hoehr, N. F., Siqueira, L. H., Ozelo, M. C. \& de Padua Mansur, A. Annichino-Bizzacchi J. M. Association between estrogen receptor alpha and beta gene polymorphisms and deep vein thrombosis. Thromb. Res. 120, 639-645 (2007).

27 Rexrode, K. M., Ridker, P. M., Hegener, H. H., Buring, J. E., Manson, J. E. \& Zee, R. Y. Polymorphisms and haplotypes of the estrogen receptor-beta gene (ESR2) and cardiovascular disease in men and women. Clin. Chem. 53, 1749-1756 (2007).

28 Nilsson, M., Naessen, S., Dahlman, I., Linden Hirschberg, A., Gustafsson, J. A. \& Dahlman-Wright, K. Association of estrogen receptor beta gene polymorphisms with bulimic disease in women. Mol. Psychiatr. 9, 28-34 (2004).

29 Almeida, S., Franken, N., Zandona, M. R., Osorio-Wender, M. C. \& Hutz, M. H. Estrogen receptor 2 and progesterone receptor gene polymorphisms and lipid levels in women with different hormonal status. Pharmacogenomics J. 5, 30-34 (2005).

30 Grundy, S. M., Becker, D., Clark, L. T., Cooper, R. S., Denke, M. A., Howard, J. et al. Third Report of the National Cholesterol Education Program (NCEP) Expert Panel on Detection, Evaluation, and Treatment of High Blood Cholesterol in Adults (Adult Treatment Panel III) final report. Circulation 106, 3143-3421 (2002).

31 Shi, Y. Y. \& He, L. SHEsis, a powerful software platform for analyses of linkage disequilibrium, haplotype construction, and genetic association at polymorphism loci. Cell Res. 15, 97-98 (2005).

32 Faul, F., Erdfelder, E., Lang, A. G. \& Buchner, A. G*Power 3: a flexible statistical power analysis program for the social, behavioral, and biomedical sciences. Behav. Res. Methods 39, 175-191 (2007).

33 Di Croce, L., Bruscalupi, G. \& Trentalance, A. Independent behavior of rat liver LDL receptor and HMGCoA reductase under estrogen treatment. Biochem. Biophys. Res. Commun. 224, 345-350 (1996).

34 Mendelsohn, M. E. Protective effects of estrogen on the cardiovascular system. Am. J. Cardiol. 89, 12E-17E; discussion 17E-18E (2002).

35 Demissie, S., Cupples, L. A., Shearman, A. M., Gruenthal, K. M., Peter, I., Schmid, C. $\mathrm{H}$. et al. Estrogen receptor-alpha variants are associated with lipoprotein size distribution and particle levels in women: the Framingham Heart Study. Atherosclerosis 185, 210-218 (2006).

36 van Meurs, J. B., Schuit, S. C., Weel, A. E., van der Klift, M., Bergink, A. P., Arp, P. P. et al. Association of $5^{\prime}$ estrogen receptor alpha gene polymorphisms with bone mineral density, vertebral bone area and fracture risk. Hum. Mol. Genet. 12, 1745-1754 (2003).

37 Schuit, S. C., van Meurs, J. B., Bergink, A. P., van der Klift, M., Fang, Y., Leusink, G. et al. Height in pre- and postmenopausal women is influenced by estrogen receptor alpha gene polymorphisms. J. Clin. Endocrinol. Metab. 89, 303-309 (2004).

38 Weel, A. E., Uitterlinden, A. G., Westendorp, I. C., Burger, H., Schuit, S. C., Hofman, A. et al. Estrogen receptor polymorphism predicts the onset of natural and surgical menopause. J. Clin. Endocrinol. Metab. 84, 3146-3150 (1999).

39 Jones, D. R., Schmidt, R. J., Pickard, R. T., Foxworthy, P. S. \& Eacho, P. I. Estrogen receptor-mediated repression of human hepatic lipase gene transcription. J. Lipid Res. 43, 383-391 (2002)

40 Shearman, A. M., Cooper, J. A., Kotwinski, P. J., Humphries, S. E., Mendelsohn, M. E., Housman, D. E. et al. Estrogen receptor alpha gene variation and the risk of stroke. Stroke 36, 2281-2282 (2005).

41 Yoshihara, R., Utsunomiya, K., Gojo, A., Ishizawa, S., Kanazawa, Y., Matoba, K. et al. Association of polymorphism of estrogen receptor-alpha gene with circulating levels of adiponectin in postmenopausal women with type 2 diabetes. J. Atheroscler. Thromb. 16, 250-255 (2009).

42 Hayashi, K., Maeda, S., Iemitsu, M., Otsuki, T., Sugawara, J., Tanabe, T. et al. Sex differences in the relationship between estrogen receptor alpha gene polymorphisms and arterial stiffness in older humans. Am. J. Hypertens. 20, 650-656 (2007).

43 Ferrero, V., Ribichini, F., Matullo, G., Guarrera, S., Carturan, S., Vado, A. et al. Estrogen receptor-alpha polymorphisms and angiographic outcome after coronary artery stenting. Arterioscler. Thromb. Vasc. Biol. 23, 2223-2228 (2003).

44 Lamon-Fava, S., Asztalos, B. F., Howard, T. D., Reboussin, D. M., Horvath, K. V. Schaefer, E. J. et al. Association of polymorphisms in genes involved in lipoprotein metabolism with plasma concentrations of remnant lipoproteins and HDL subpopulations before and after hormone therapy in postmenopausal women. Clin. Endocrinol. (2009) (e-pub ahead of print; doi:10.1111/j.1365-2265.2009.03644.x).

45 Pan, A., Franco, O. H., Ye, J., Demark-Wahnefried, W., Ye, X., Yu, Z. et al. Soy protein intake has sex-specific effects on the risk of metabolic syndrome in middle-aged and elderly Chinese. J. Nutr. 138, 2413-2421 (2008).

46 Domingues-Montanari, S., Subirana, I., Tomas, M., Marrugat, J. \& Senti, M. Association between ESR2 genetic variants and risk of myocardial infarction. Clin. Chem. 54, 1183-1189 (2008).

47 Lu, H., Higashikata, T., Inazu, A., Nohara, A., Yu, W., Shimizu, M. et al. Association of estrogen receptor-alpha gene polymorphisms with coronary artery disease in patients with familial hypercholesterolemia. Arterioscler. Thromb. Vasc. Biol. 22, 817-823 (2002).

Supplementary Information accompanies the paper on Journal of Human Genetics website (http://www.nature.com/jhg) 